\title{
Our Experiences with Congenital Midline Nasal Dermoid Sinus Cyst
}

${ }^{1}$ Yashwant Maru, ${ }^{2}$ Yamini Gupta

\begin{abstract}
Introduction: Nasofrontal dermoid sinus cysts (NDSC) are rare congenital malformations. NDSC $s$ are distinct from other facial dermoids in their potential for involving deeper contiguous structures and intracranial extension. The development of this congenital midline sinus of dorsum of nose has opened a new horizon in current concepts of embryology.
\end{abstract}

Objective: To study the embryological origin, presentation, treatment, and genetic associations of three cases of these sinus cysts.

Clinical presentation: This paper presents our experiences with managing three patients who presented with opening on nasal dorsum with recurrent swelling and purulent discharge from it. Imaging studies in these patients indicated a midline anterior nasal sinus tract with cranial dilatation but no intracranial connection. They were successfully managed surgically.

Conclusion: Nasofrontal dermoid sinus cysts have a unique embryological origin. A midline basal frontal dermoid associated with a dimple or sinus opening on the nasal dorsum with or without protruding hair and sebaceous discharge is the classical presentation. The purpose of this report is to emphasize that, though rare nasofrontal dermoid sinus cysts do occur in our practice and their clinical importance from rhinology point of view is their potential for intracranial communication.

Keywords: Nasal midline sinus, Congenital nasal sinus, Development.

How to cite this article: Maru Y, Gupta Y. Our Experiences with Congenital Midline Nasal Dermoid S inus Cyst. Clin R hinol An Int J 2014;7(1):43-46.

\section{Source of support Nil}

Conflict of interest None

\section{INTRODUCTION}

Midline congenital lesion of the nose is a rare congenital anomaly. The incidence of this rare anomaly is estimated as 1 per 20,000 to 40,000 live births. ${ }^{1}$ They consist of gliomas, encephaloceles, and nasal dermoid sinus cysts. ${ }^{2}$

\footnotetext{
${ }^{1}$ P rofessor and Head, ${ }^{2}$ Assistant Professor

1,2Department of ENT, MGM Medical College, Indore, Madhya Pradesh, India
}

Corresponding Author: Yamini Gupta, Assistant Professor Department of ENT, MGM Medical College, Indore, Madhya Pradesh, India, Phone: +91-7314066708, e-mail: dryamini10@ gmail.com
$N$ asal dermoid sinus cysts account for 1 to $3 \%$ of dermoid cysts overall and 11 to $12 \%$ of head and neck dermoids. ${ }^{2}$ M ost lesions are diagnosed within the first 3 years of life but in some cases the diagnosis can be delayed. ${ }^{3}$ Though central nervous system's (CNS) involvement in gliomas and encephalocel es is well-known but, nasal dermoid sinus cyst (NDSC) are important because of their potential for intracranial involvement. $^{2}$

NDSC originates from ectoderm that forms from neuroectodermal and ectodermal inseparation. ${ }^{4}$ The most widely accepted etiologic theory centers on the prenasal space and fonticulus, which forms between the anterior wall of the nasal skeleton and the frontal and nasal bones. ${ }^{5}$ It presents as midline nasal pit, fistula, or infected mass any where from glabella to columella, distal one-third of the nasal dorsum being the most common site.

We present review of three patients with diagnosis of this rare congenital nasal midline lesion and comprehensive discussion of the embryogenesis, pathogenesis, diagnosis, and surgical management of the NDSC.

\section{Patients and Methods}

A retrospective analysis of patient demographics, clinical presentation, preoperative investigations and surgical procedures undertaken of three patients was done.

\section{CASE REPORTS}

\section{Case 1}

A 12 years male presented in ENT OPD with complaints of pit present in lower half of dorsum of nose since birth associated with recurrent discharge from opening, diffuse swelling and pain over dorsum of nose. Examination of nose revealed opening of a sinus in the midline on the dorsum of nose in supratip region with diffuse, tender erythematous swelling superior to the opening. Rest ENT examination was WNL. A fter control of acute infection sinogram was done. Sinus was catheterized with polythene catheter up to $1 \mathrm{~cm}$ (Fig. 1). Sinogram with Conray 280 was done which revealed a linear shadow of dye $2 \mathrm{~cm}$ long extending from supratip region to just short of nasal bone (Fig. 2). There was no evidence of intracranial or intranasal communication. Under GA surgical excision of sinus tract was done. An elliptical incision was given around the sinus opening and 


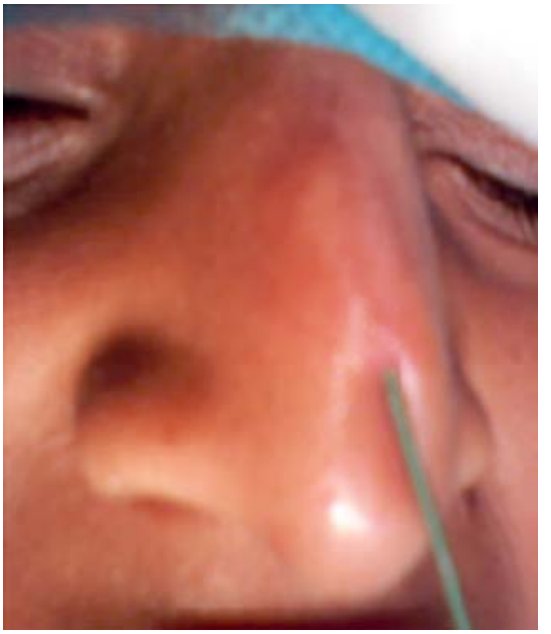

Fig. 1: Sinus over dorsum of nose catheterized with polythene catheter up to $1 \mathrm{~cm}$

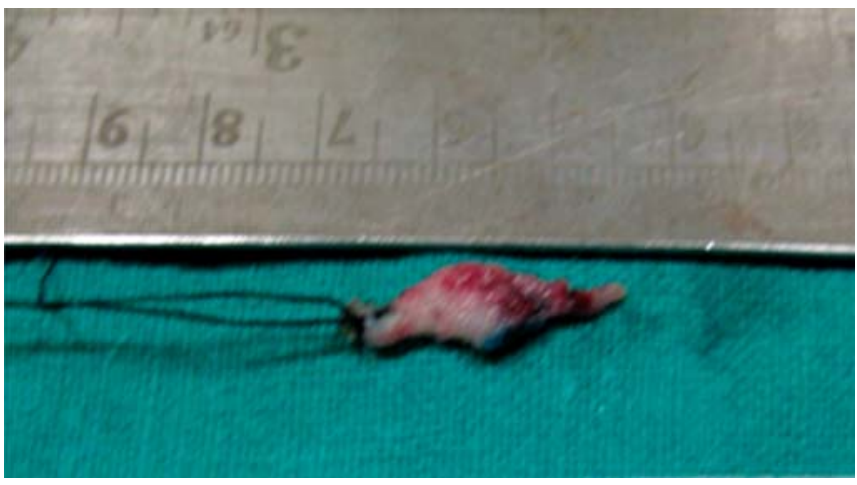

Fig. 3: Excised tract with cranial dilation into a sac

using the probe as a guide, the tract was dissected out with blunt and sharp dissection after adding a vertical extension to the elliptical incision. Tract was dilated into a sac cranially and was excised in toto (Fig. 3). Postoperative period remained uneventful. On 3 years follow-up no recurrence or complication was noted.

\section{Case 2}

A 3 years boy presented in ENT OPD with complaints of swelling over dorsum of nose and recurrent discharge from opening on dorsum of nose for last 1 year though mother noted pit on nasal dorsum at birth only. Examination revealed a sinus opening in midline of nose with surrounding zone of inflammation and swelling (Fig. 4). A fter performing all routine investigations sinogram was done which revealed a blind tract extending from midline of nose supra tip region cranially to just short of nasion. There was no intranasal communication. Sinus tract with cranial dilatation to form a dermoid cyst was surgically excised in toto. Intraoperatively a bony defect in midline with no intranasal or intracranial communication was identified (Fig. 5).

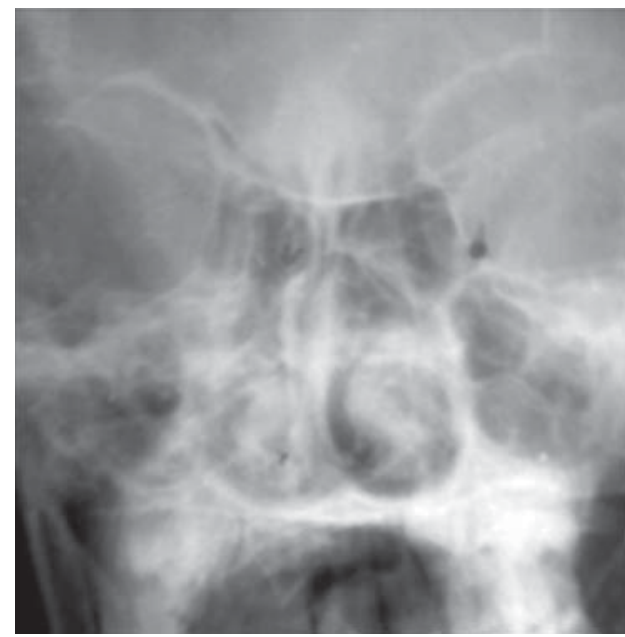

Fig. 2: Sinogram with Conray 280 was done which revealed a linear shadow of dye $2 \mathrm{~cm}$ long extending from supratip region to just short of nasal bone

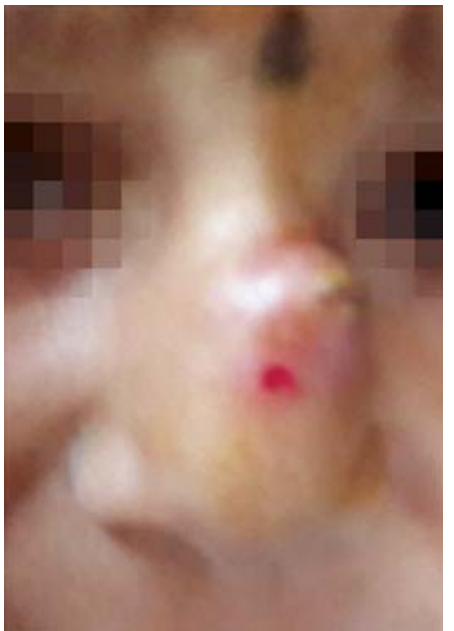

Fig. 4: Sinus opening in midline of nose with surrounding zone of inflammation and swelling

\section{Case 3}

A 4 years female child presented with a sinus opening on dorsum of nose about $2 \mathrm{~cm}$ cranially from tip of nose since birth. The sinuses discharged intermittently. Various attempts were made at peripheral hospitals to control the discharge conservatively but failed. Through sinus on dorsum of nose a fine polythene catheter could be easily passed for about 1.5 $\mathrm{cm}$. There was no other associated congenital abnormality. $X$-ray nasal bone was normal. The dorsal nasal sinus was removed surgically through an elliptical incision around the sinus. The tract was subcutaneously skirting underneath nasal bone. The left nasal bone was partially nibbled to expose deeper part of tract. The blind dilated cyst like other end was also dissected out which was filled with cheesy material. The wound was sutured and postoperative period remained uneventful. 


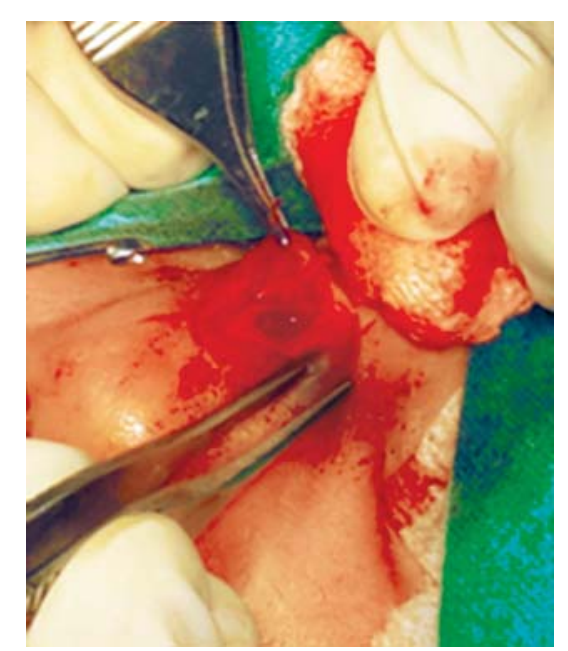

Fig. 5: Intraoperative bony defect in midline with no intranasal or intracranial communication was identified

\section{RESULTS}

$M$ ean age at presentation and surgery was 6.3 years. $M$ ale female ratio was 2:1. A II three cases presented with opening on nasal dorsum with recurrent swelling and purulent discharge from it. Sonogram done in two patients revealed blind sinus tract. They were successfully managed surgically. A Il three patients show ed good outcome with local excision of sinus tract with dermoid cyst only. All of them showed no intracranial extension and there were no associated congenital anomalies. M ean follow-up of 2 years showed no deep recurrences (Table 1 ).

\section{DISCUSSION}

A mong the midline deformities of the nose, congenital midline sinuses of the dorsum are rare. Although usually detected at birth, they may not be recognized until well into adulthood. The diagnosis for most of the NDSCs is made in the first 3 years of childhood. The oldest patient in the literature is a 56-year old patient with intracranial extension. ${ }^{6}$ There are some reports about male predominance. ${ }^{7}$ In our study also, male predominance was seen with male female ratio of 2:1. NDSC is seen sporadically but familial cases have been reported in the literature. ${ }^{4} \mathrm{~A} / \mathrm{l}$ three of our cases were al so sporadic.

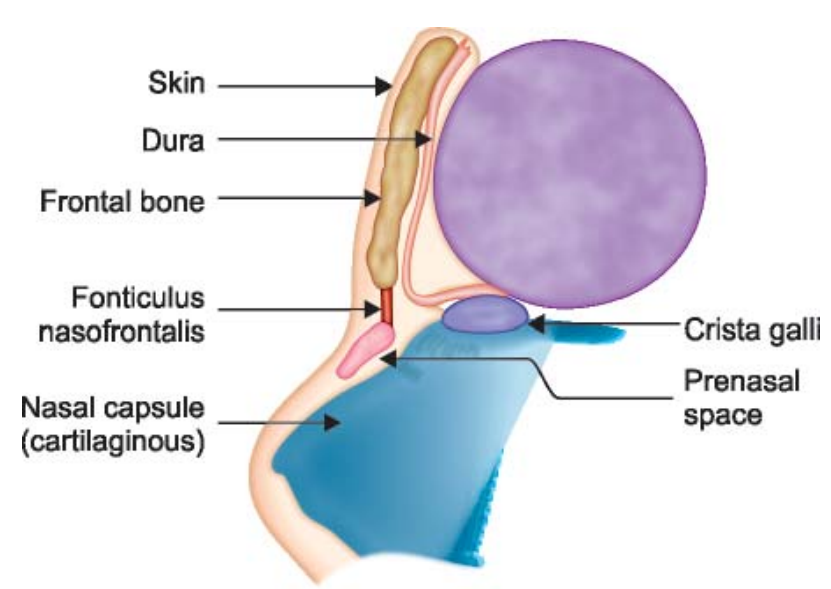

Fig. 6: Prenasal space - a potential space extending from the brain to the nasal tip

The first report about N DSC was published by B ramann in $1890 . .^{8}$ There are lots of theories like sequestration, trilaminary and prenasal, about NDSCs. The development of nose is attributed to single midline structure, the frontonasal process thus denying the possibility of fusion line that could embryologically give rise to malformations. ${ }^{9}$ The concept of nose having unpaired embryological frontonasal process has been challenged more than once. $\mathrm{H}$ andoussa ${ }^{10}$ concluded in his study that midline congenital malformations of nose like bifid nose, midline fissure, etc. are difficult to explain on present concept of embryology and suggested bilateral origin of nose. The most accepted theory is Pratt's prenasal theory. ${ }^{2}$ Pratt described the common embryologic pathway of gliomas, encephaloceles and nasofrontal dermoid sinus tract. $^{3,8}$ The nasal bones are separated from the adjacent cartilaginous nasal capsule by a Prenasal space (Fig. 6). This potential space extends from the brain to the nasal tip. During the extension of dura between the unconnected bones in the skul lbase to nasal region the dura is related with dermis in the nasal tip. Dura normally separates from skin dermis during ossification. If the bone tissue could not separate the dura from dermis during the ossification, it may pull the ectoderm creating an persistent ectodermal tract extending from the external surface of the nose under the nasal bones

Table 1: Showing comparative clinical details of three patients

\begin{tabular}{|c|c|c|c|}
\hline & Patient 1 & Patient 2 & Patient 3 \\
\hline Age/Sex & 12 Year/M & 03 Year/M & 04 Year/F \\
\hline $\begin{array}{l}\text { Opening on dorsum of nose } \\
\text { since birth }\end{array}$ & + & + & + \\
\hline $\begin{array}{l}\text { Recurrent swelling and } \\
\text { discharge from sinus }\end{array}$ & + & + & + \\
\hline $\begin{array}{l}\text { Distance of sinus tract from } \\
\text { opening }\end{array}$ & $2 \mathrm{~cm}$ & $1 \mathrm{~cm}$ & $1.5 \mathrm{~cm}$ \\
\hline Sinogram & + & + & \\
\hline Associated anomalies & Nil & Nil & Nil \\
\hline Treatment given & $\begin{array}{l}\text { Local surgical excision of sinus } \\
\text { tract with dermoid cyst }\end{array}$ & $\begin{array}{l}\text { Local surgical excision of sinus } \\
\text { tract with dermoid cyst }\end{array}$ & $\begin{array}{l}\text { Local surgical excision of sinus } \\
\text { tract with dermoid cyst }\end{array}$ \\
\hline
\end{tabular}


or through them into the prenasal space and into the cranial cavity through the crista galli. ${ }^{5}$

NDSC s are typically seen as midline masses. They usually have a sinus opening in the nasal dorsum. ${ }^{4}$ Distal onethird of the nasal dorsum is the most common site. Dermoid sinus cysts of the nose present as a midline nasal pit, fistula, or infected mass located anywhere from the glabella to the nasal columella which may secrete cheesy material, pus. ${ }^{8}$ In all three cases of our study sinus pit was present on nasal dorsum but, swelling was present in one patient.

Differential diagnosis includes nasal glioma and encephalocele. $\mathrm{N}$ asal gliomas are firm, noncompressible, and do not transilluminate but, may have overlying telangiectasia. Encephaloceles may be bluish or red, soft, compressible, enlarge with crying, and have a positive Frustenberg test.

These congenital midline malformations of nose are clinically important because of their potential connection to central nervous system. The ratio of the intracranial extension is controversial. ${ }^{2}$ Suspicion of intracranial extension is important for every patient with NDSC. CT and/or M RI are helpful to determine the extension. ${ }^{4}$

There is no association of a syndrome with the formation of the NDSC. But, 5 to $41 \%$ of patients show associated congenital anomalies. These associations have been reported with different ratios in the literature. ${ }^{8}$ The associated congenital anomalies that have been reported include aural atresia, cleft lip/palate, tracheoesophageal fistulas, spinal column abnormalities, mental retardation, dermal cyst of the frontal lobe, cardiac and genital anomalies. None of our cases had associated congenital anomalies.

The treatment of the NDSC is surgical excision. ${ }^{3,4}$ Surgical resection indicated for the simple reasons of Cosmesis and to avoid/treat complications like local infections, meningitis, cerebral abscess, etc. Surgical strategy depends on the location and extent of the lesion, ranging from local excision to a combined intracranialextracranial approach. For good outcome, surgical resection of complete sinus tract with cyst is effective in management of patients with no intracranial extension as was done in all three of our patients. Recurrence is uncommon and often easily managed.

\section{CONCLUSION}

Congenital $\mathrm{N}$ asofrontal dermoid sinus cysts is a rare congenital anomaly seen in practice but, they do occur.

They have a unique embryological origin. A midline basal frontal dermoid associated with a dimple on the nasal surface with or without protruding hair and sebaceous discharge is the pathognomonic presentation.

Preoperative evaluation is essential to rule out intracranial extension. A lthough concomitant anomalies and familial clustering have been described, most cases are of spontaneous occurrences.

These cases were very unusual in themselves in being totally extranasal, extracranial and extending from supra tip area with cranial dilatation into a sac.

For good outcome, surgical resection of complete sinus tract with cyst is effective in management of these patients.

\section{REFERENCES}

1. Zapata S, K earns DB. Nasal dermoids. Curr O pin Otolaryngol Head N eck Surg 2006;14:406-411.

2. Emel CT, Ömer TS, Güleser SA O, Hakan K. The management of rare nasal mass - nasal dermoid sinus cysts: open rhinoplasty. Rare Tumors. 2009 Dec 28;1(2):e40.

3. Post G, M cM ains K C, K ountakis SE. A dult nasal dermoid sinus cyst. A m J Otolaryngol 2005;26:403-405.

4. Bilkay U, Gundogan H, Ozek C, et al. Nasal dermoid sinus cysts and the role of open rhinoplasty. A nn Plast Surg 2001:478-414.

5. Tew fik TL, M eyers AD. Congenital malformations of the Nose. emedicine.medscape.com/article/837236.

6. Hacker DC, F reeman J L. Intracranial extension of a nasal dermoid sinus cyst in a 56-year-old man. Head Neck 1994;16:366-371.

7. DenoyelleF, Ducroz V, Roger G, Gara-bedian E N. Nasal dermoid sinus cysts in children. Laryngoscope 1997;107:795-800.

8. Hanikeri $M$, Waterhouse $N$, K irkpatrick $N$, et al. The management of midline transcranial nasal dermoid sinus cysts. B I J Plast Surg 2005;58:1043-1050.

9. M aru $Y K$, et al. Congenital midline sinus in the dorsum of nose. Indian J Otolaryngology and Head N eck Surgery 1980; 32(2):58.

10. Handuosa AS. M idline congenital malformations of nose. J Laryngology and Otology 1949;63:596. 